\title{
Georgia 0’Keeffe, Black Cross with Stars and Blue
}

Jeffrey Richmond-Moll

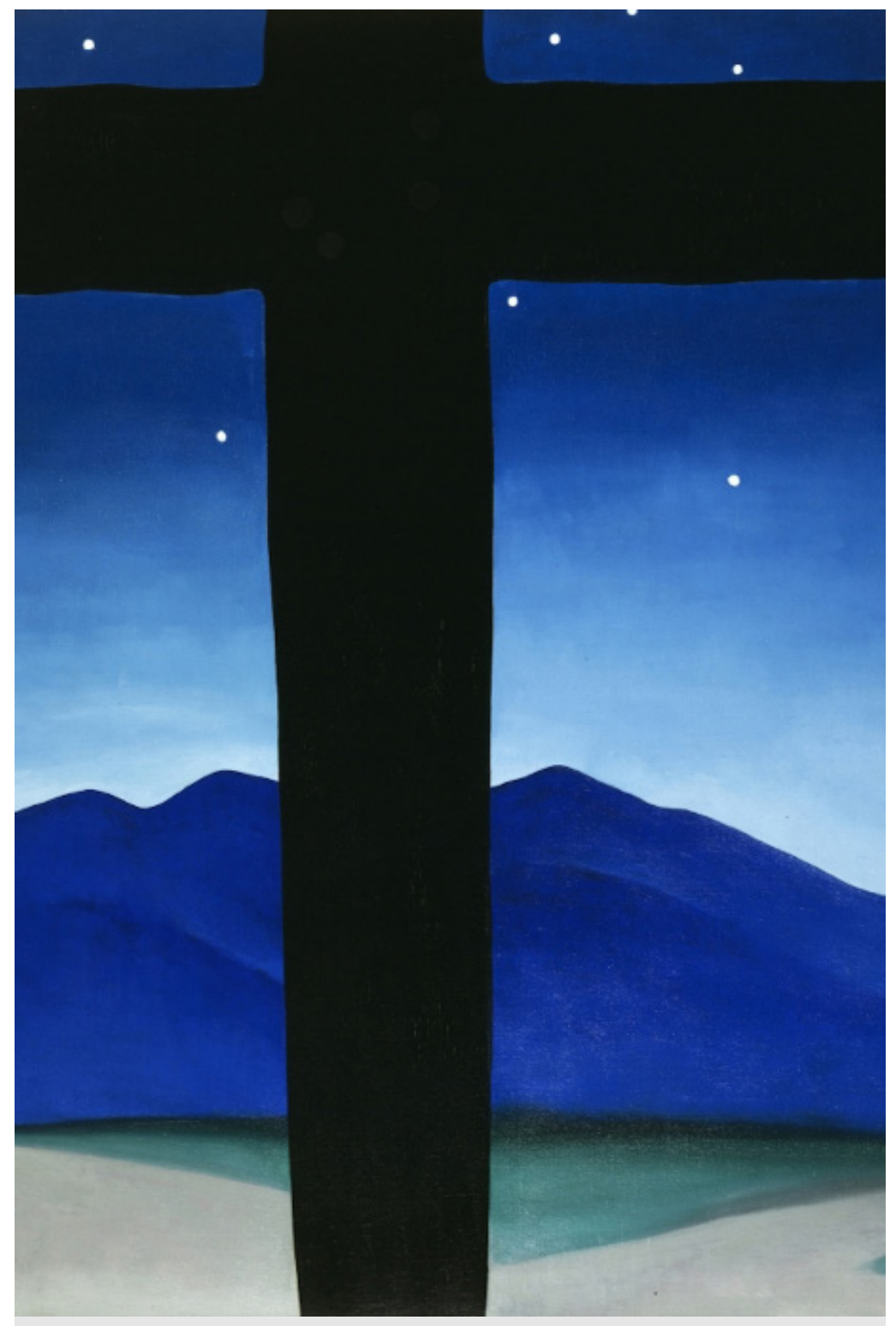

Fig. 1 Georgia O'Keeffe, Black Cross with Stars and Blue, 1929. Oil on canvas, 40 x 30 in. Private Collection

In 1929, on her first visit to New Mexico, the American artist Georgia O'Keeffe (18871986) observed the animate potential of the region's religious material culture. While in Taos that summer, O'Keeffe occupied La Casa Rosita, the guesthouse at the compound of her friend and patron Mabel Dodge Luhan. From her room and studio O'Keeffe had a clear view north to Taos Mountain, as well as to the morada (meetinghouse) of the Hermanos de la Fraternidad Piadosa de Nuestro Padre Jesús Nazareno (also known as the "Penitentes"), which was situated between them. ${ }^{1}$ A contemporary photograph in Mabel Luhan's papers at Yale University's Beinecke Library shows one of the three 
crosses that stood beside the Penitente morada, with the undulating ridge of the Sangre de Cristo range visible in the distance (Fig. 2). ${ }^{2}$ Because Mabel's husband, Tony Luhan, was Taos Puebloan, guests to the Luhan home experienced unique access to these and other sacred places, which were located on Pueblo lands and were otherwise typically off-limits to Anglo visitors. Exhilarated by these encounters and by automobile excursions further afield with Tony and her artist-friend Rebecca Salsbury James (then Rebecca Strand), O'Keeffe began at least twenty-three paintings during her four-month stay that summer, including four canvases of Penitente crosses erected at Taos and near Alcalde, New Mexico, as well as at Cameron, Arizona. ${ }^{3}$

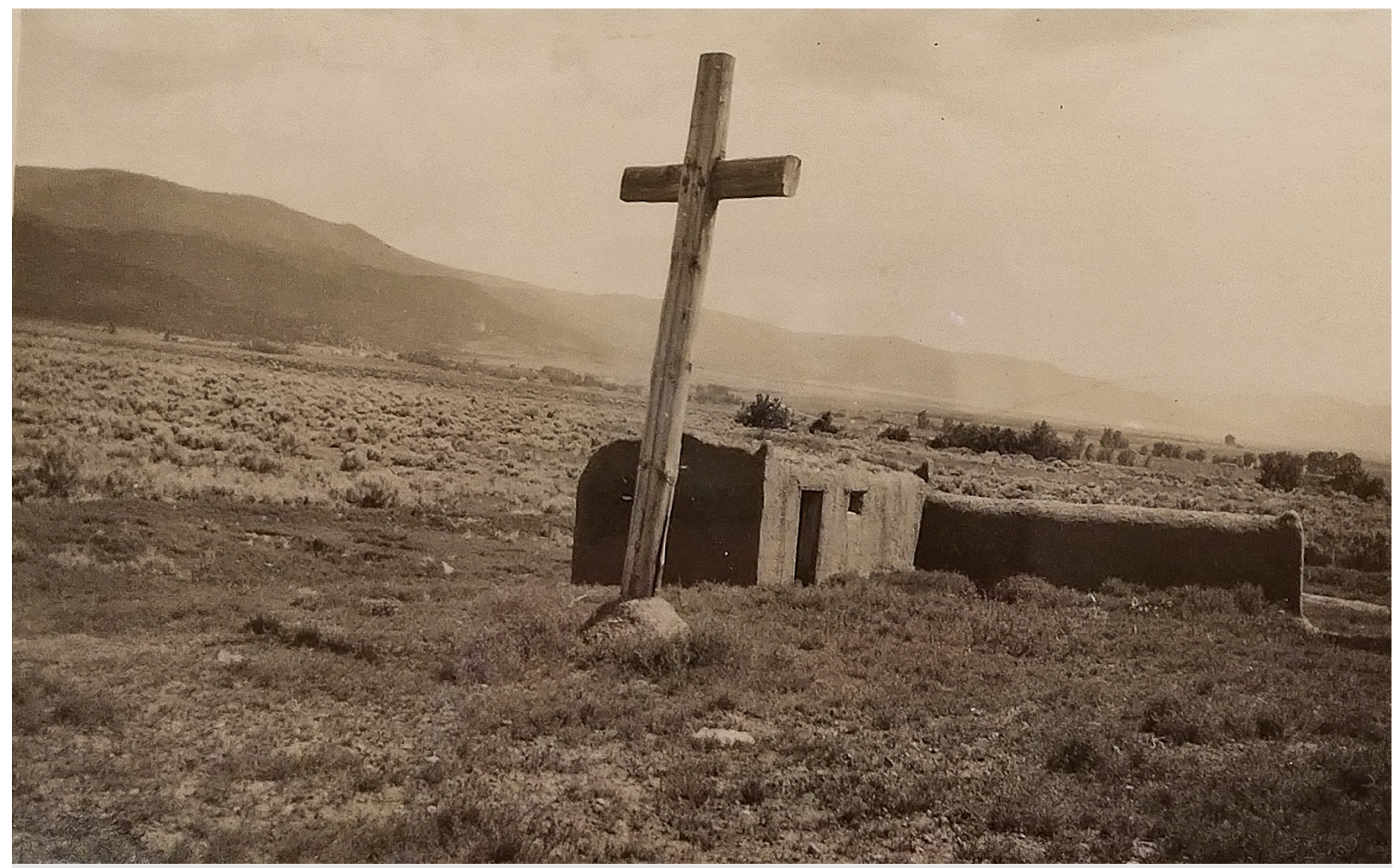

Fig. 2 Unknown photographer, Penitente Cross and Morada behind Mabel Dodge Luhan's property at Taos, ca. 1924-50. Mabel Dodge Luhan Papers, MSS 196, box 79, folder 2194, Yale Collection of American Literature, Beinecke Rare Book and Manuscript Library, Yale University.

These cross paintings are unique to O'Keeffe's first summer in the Southwest. After 1929, she would never paint another Penitente cross, even as she returned to New Mexico (at first to visit and eventually to reside permanently) across the following six decades. Typically compared in the literature to her New York skyscraper pictures for their monumentality, stark angularity, and nocturnal tonality, the crosses fill her canvases to their extremities. For scholars, these "unitary artifacts" encapsulate a "spirit of place," particularly the imposing religiosity of Southwestern Catholicism.4 "I saw the crosses so often - and often in unexpected places-like a thin dark veil of the Catholic Church spread over the New Mexico landscape," recalled O'Keeffe, who was raised as a Catholic and remained sympathetic toward the religious communities of the Southwest throughout her lifetime. ${ }^{5}$ 
But O'Keeffe's cross paintings also visually and conceptually register the latent power of these ritual objects. By conveying a strong sense of movement, these compositions align O'Keeffe's physical encounters with crosses in the landscape that summer with the mobile properties of the crosses in their ceremonial contexts. "One evening," O'Keeffe recalled of the night when she was inspired to paint her first two cross paintings, while staying at Mabel's,

we walked back of the morada toward a cross in the hills. . . The cross was large enough to crucify a man, with two small crosses-one on either side. It was in the late light and the cross stood out-dark against the evening sky. If I turned to the left, away from the cross, I saw the Taos mountain-a beautiful shape. I painted the cross against the mountain though I never saw it that way. I painted it with a red sky and I painted it with a blue sky and stars. ${ }^{6}$

In the two canvases that she painted following this twilight excursion, Black Cross with Stars and Blue (Fig. 1) and Black Cross with Red Sky (Fig. 3), O'Keeffe constructs an imagined, synthetic vision, combining the looming Penitente cross behind Mabel's home and the peaks beyond. Indeed, as O'Keeffe notes, she did not see them in this specific arrangement. Monumentally inscribed against a saturated crepuscular sky, O'Keeffe's crosses have moved (metaphorically speaking) across the landscape to stand before the sacred mountain, just as she herself turned from one spot on the land to another in mentally composing the picture. ${ }^{7}$ The "late light" of these two pictures also conveys the temporal dimension of O'Keeffe's pair of pictures. Silhouetted first against a red, sundown sky and then a blue, starry one, O'Keeffe's two crosses register the passage of nightfall, thus mapping the gradual unfolding, in time and space, of her walk about the cross that evening. When read sequentially, the slightly different standpoints of the two crosses also reiterate this passage of time: the cross in the red canvas approaches the crossroads in the foreground, while the cross in the blue canvas is nearly centered upon it.

It was, after all, the movement of these Penitente crosses across the landscape of New Mexico in local rituals that gave them their fullest spiritual meaning. Founded in the early 1800 s by Christianized nontribal native peoples of slave ancestry and other exiled Pueblo Indians, the Penitentes were a lay Catholic brotherhood that emerged in the priestly vacuum created by the withdrawal of the Franciscan order from New Mexico in 1790. The Brotherhood's rituals centered upon the remembrance of Christ's Passion, and accordingly emphasized human submission to suffering through rituals of mortification, flagellation, cross-bearing, and reenacted crucifixions. As the Catholic Church began to reassert its presence in the region from the mid-180os onward, the Penitentes would continue their Holy Week processions, but also sought the privacy of their moradas for their year-round devotions. ${ }^{8}$ The crosses erected outside the morada at Taos were processional crosses, just three of the multitude that dotted the region and were picked up from their bases and carried along on holy days, especially during Holy Week rituals. ${ }^{9}$ Created out of her own physical movements, O'Keeffe's cross paintings reify that ceremonial context. 


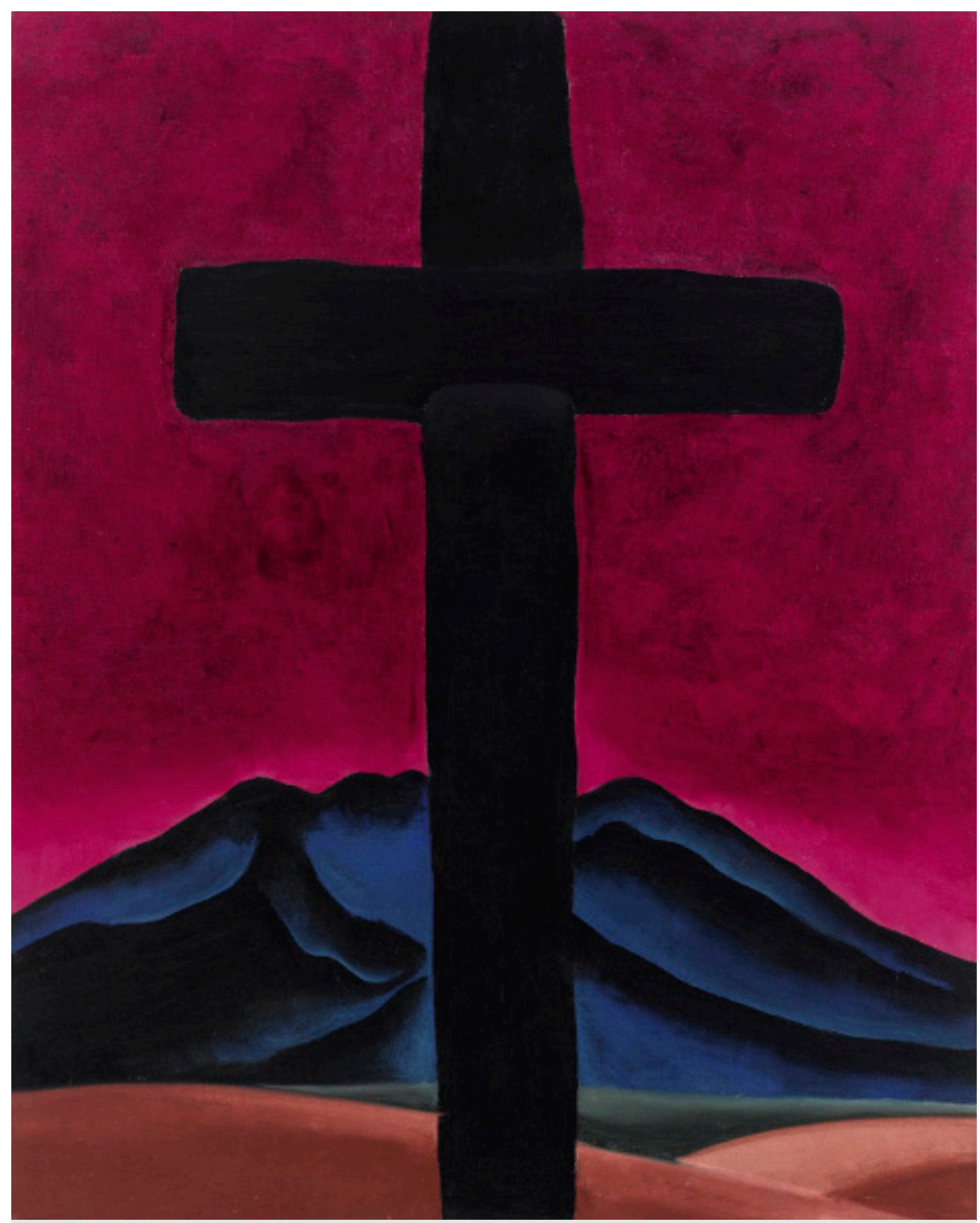

Fig. 3 Georgia O’Keeffe, Cross with Red Sky (Black Cross with Red Sky), 1929. Oil on canvas, $40 \times 32$ in. Private Collection.

The extreme collapse of the foreground cross and background mountain here and in Black Cross, New Mexico (1929; Art Institute of Chicago, acc. no. 1943.95) further indexes a sense of movement through space, registering both O'Keeffe's perambulations and the crosses' processional movements in this landscape. As Robin Kelsey has written regarding Arthur Schott's U.S.-Mexico boundary surveys from the 1850s, such compact renderings of the landscape, which eschew the full continuity of spatial recession by superimposing foreground elements directly upon background ones, accelerate the viewer's own visual traversal of pictorial space. O'Keeffe's black crosses are therefore experiential, physio-optical pictures. Her critics, upon first seeing them, recognized this transcendent quality. New York Times critic Edward Alden Jewell praised how her crosses "pierce[d] through to sheer spiritual experience," while a writer from the New York Sun declared, "A gallery is no place for [the 'Crosses']. [They] ought to be viewed 
in a church."10 They exude this spiritual, experiential potency because, as Emily Ballew Neff notes, O'Keeffe's paintings always depict the landscape through the lens of what has happened there. ${ }^{11}$ Indeed, O'Keeffe herself spoke of her endeavors to insert into a picture "the life that has been lived in a place." ${ }^{2}$ The viewer ought to see her black crosses, then, as marking off a world of human action and pious ceremony; as living, moving objects. As the foreground of Black Cross with Stars and Blue also indicates, this cross stands at a crossroads, a space characterized by the temporary halt and resumption of movement.

O'Keeffe's black crosses exist, then, at the cusp of stillness and motion, having merely been paused in the artist's mind's-eye and silhouetted against Taos Mountain. Meanwhile, another of her crosses, Grey Cross with Blue (Fig. 4), towers above the horizon, its attenuated, penumbral form leaning forward as if into the viewer's own space. Like a bowed, swaying cross in a related sketch (1929; Georgia O'Keeffe Museum, acc. no. 1997.06.31)-and unlike the more stationary format and stable viewing position of the black crosses-the Grey Cross looks as if it is being held aloft or even carried at the head of a procession. This may be the same wayside cross to which O'Keeffe referred in a note to Mabel on her return to New Mexico in 1930: "I painted a light cross that I often saw on the road near Alcalde. I looked for it recently but it is not there."13 Perhaps the real grey cross had been picked up and carried off on some procession, resuming its peregrinations in the world.

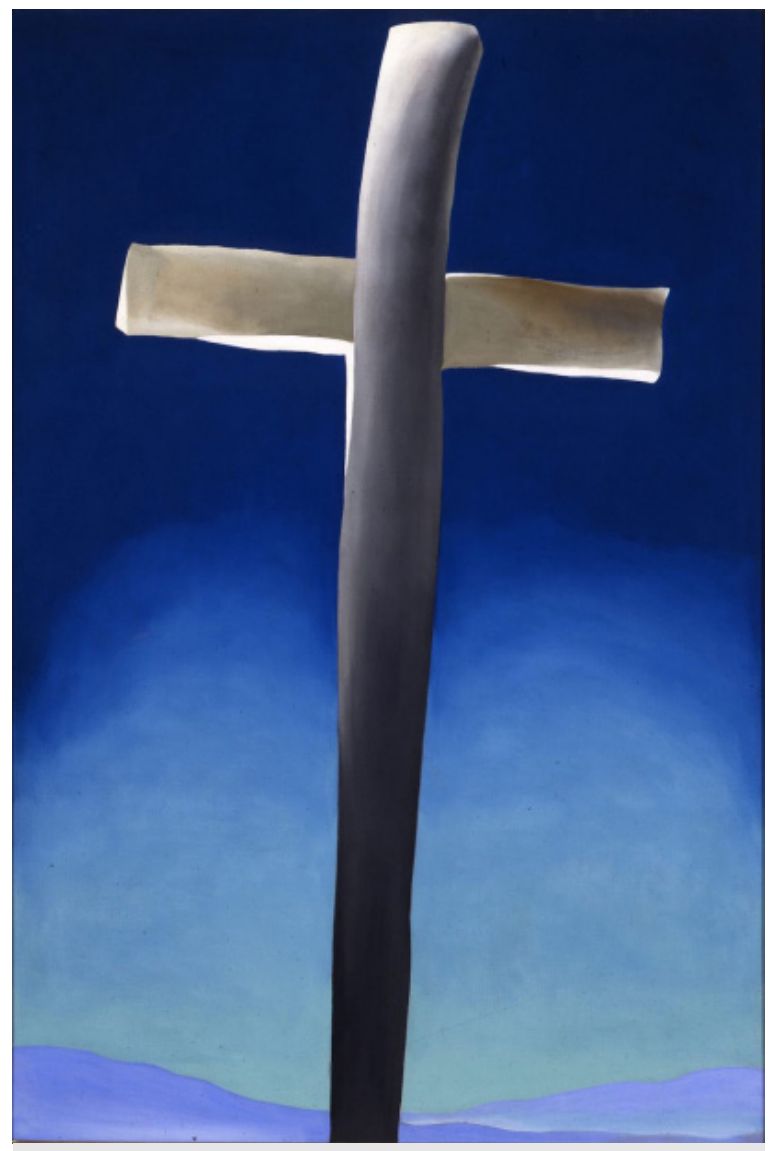

Fig. 4 Georgia O’Keeffe, Grey Cross with Blue, 1929. Oil on canvas, 36 x 24 in. The Albuquerque Museum. 


\section{Citation Guide}

1. Jeffrey Richmond-Moll, “Georgia O’Keeffe, Black Cross with Stars and Blue,” Object Narrative, in MAVCOR Journal 2, no. 1 (2018), doi:10.22332/mav.obj.2018.1

Richmond-Moll, Jeffrey. “Georgia O'Keeffe, Black Cross with Stars and Blue.” Object Narrative. In MAVCOR Journal 2, no. 1 (2018), doi:10.22332/mav.obj.2018.1

\section{Notes}

1. The Penitentes, whose name literally translates as the "Brothers of the Pious Fraternity of Our Father Jesus of Nazareth," are a lay-religious fraternal organization. The brotherhood emerged following the withdrawal of the Franciscan order from New Mexico in 1790, and, until the Catholic Church's return around 1850, Hermanos presided over rites like baptism and burials, and functioned as an integrative religious and social force in the region. After 1850, their rituals became increasingly private, with the exception of annual public processions, accompanied by flagellation and simulated crucifixions, during Holy Week.

2. Walter Ufer's Builders of the Desert (ca. 1923; Terra Foundation for American Art) likely depicts the construction of Luhan's house at Taos, with a view of the morada, crosses, and mountain on Taos Pueblo territory in the distance.

3. Barbara Buhler Lynes, "Introduction," in Georgia O'Keeffe in New Mexico: Architecture, Katsinam, and the Land, eds. Barbara Buhler Lynes and Carolyn Kastner (Santa Fe: Museum of New Mexico Press, and Georgia O'Keeffe Museum, 2012), 15. Emily Ballew Neff, The Modern West: American Landscapes, 1890-1950 (New Haven and London: Yale University Press in association with the Museum of Fine Arts, Houston, 2006), 191. O'Keeffe's drawings from this trip in the so-called Schneider Sketchbook (Georgia O'Keeffe Foundation) also include several crosses on Taos land. See Barbara Buhler Lynes, Georgia O'Keeffe: Catalogue Raisonné (New Haven, Conn.: Yale University Press in association with the National Gallery of Art, Washington, D.C., and the Georgia O'Keeffe Foundation, Abiquiu, NM, 1999), vol. 2, 1053-61, specifically nos. 1842, 1844, 1846, 1847-48.

4. Wanda Corn, The Great American Thing: Modern Art and National Identity, 19151935 (Berkeley and London: University of California Press, 1999), 164, 257-258. For a more recent, gendered reading of O'Keeffe's cross paintings, particularly as their fractured compositions relate to the penitential male body in Southwestern rituals, see Miguel de Baca, "Blurred Boundaries: La Muerte en su Carreta as Artifact and Symbol," in Locating American Art: Finding Art's Meaning in Museums, Colonial Period to the Present, ed. Cynthia Fowler (Burlington: Ashgate, 2016), 25-26.

5. Georgia O'Keeffe, Georgia O'Keeffe (New York: Viking Press, 1976), unpaginated, text accompanying entry 64 . 
6. O'Keeffe, Georgia O’Keeffe, text opposite plate 64.

7. In a letter to her husband Alfred Stieglitz from "Los Gallos" (the Luhan's Taos compound), O'Keeffe writes, "Our walk to the cross tonight was nice." This passing reference to her evenings spent with Rebecca James, John Marin, and others at Los Gallos suggests that these walks out to the cross behind the compound occurred with some frequency, and that any picture having to do with those crosses ought to be associated with O'Keeffe's own, repeated evening wanderings across Mabel's "backyard" at Taos. See O'Keeffe to Stieglitz, [May 30]-June 1, 1929, O’Keeffe/Stieglitz Archive, MSS 85, box 85, folder 1716, Yale Collection of American Literature, Beinecke Rare Book and Manuscript Library, Yale University (hereafter YCAL).

8. Claire Farago, "Mediating Ethnicity and Culture," in Transforming Images: New Mexico Santos In-Between Worlds, eds. Claire Farago and Donna Pierce (University Park: The Pennsylvania State University Press, 2006), 24. Larry Frank, New Kingdom of the Saints: Religious Art of New Mexico, 1780-1907 (Santa Fe: Red Crane Books, 1992), 9. Marta Weigle, The Penitentes of the Southwest (Santa Fe: Ancient City Press, 1970), 3 .

\section{Frank, New Kingdom of the Saints, 4.}

10. Edward Alden Jewell, "New O'Keeffe Pictures,” New York Times, February 9, 1930, 12. "The Sign of the Cross: Georgia O'Keefe's [sic] Impressions of the Taos Region Exhibited Here," New York Sun, February 8, 1930 (n.p.). Mabel Dodge Luhan papers, MSS 196, box 95, folder 2264, YCAL.

11. Neff, The Modern West, 192.

12. Georgia O'Keeffe, quoted in Daniel Catton Rich, Georgia O'Keeffe, exh. cat. (Chicago: Art Institute of Chicago, 1943), 29.

13. O'Keeffe to Mabel Dodge Luhan, ca. 1929-30, YCAL; quoted in James Moore, "So Clear Cut Where the Sun Will Come .. . Georgia O'Keeffe's Gray Cross with Blue," Artspace 10, no. 3 (Summer 1986): 38. O'Keeffe returned to New Mexico in late April 1930, and, from June to September 1930, she was once again a guest of the Luhans at Taos. The letter appears to have been written after she arrived in the Southwest but before she reunited with Mabel that summer. 


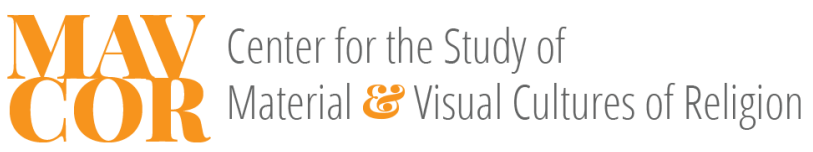

\section{Yale}

Copyright 2016 Yale University All rights reserved.

MAVCOR Joumal is a born-digital, double-blind peer-reviewed publication of the Center for the Study of Material and Visual Cultures of Religion at Yale University (mavcor.yale.edu). 